\title{
Guillaume de Digulleville, Le dit de la fleur de lis
}

\section{G. Matteo Roccati}

\section{(Q) OpenEdition}

\section{Journals}

\section{Édition électronique}

URL : http://journals.openedition.org/studifrancesi/1256

DOI : 10.4000/studifrancesi. 1256

ISSN : 2427-5856

\section{Éditeur}

Rosenberg \& Sellier

\section{Édition imprimée}

Date de publication : 1 décembre 2015

Pagination : 565

ISSN : 0039-2944

\section{Référence électronique}

G. Matteo Roccati, « Guillaume de Digulleville, Le dit de la fleur de lis », Studi Francesi [En ligne], 177 (LIX | III) | 2015, mis en ligne le 01 décembre 2015, consulté le 09 janvier 2021. URL : http://

journals.openedition.org/studifrancesi/1256 ; DOI : https://doi.org/10.4000/studifrancesi.1256

Ce document a été généré automatiquement le 9 janvier 2021.

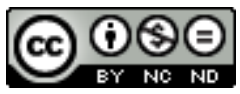

Studi Francesi è distribuita con Licenza Creative Commons Attribuzione - Non commerciale - Non opere derivate 4.0 Internazionale. 


\title{
Guillaume de Digulleville, Le dit de la fleur de lis
}

\author{
G. Matteo Roccati
}

\section{RÉFÉRENCE}

GUillaume De DigulleVille, Le dit de la fleur de lis, édité par Frédéric DUVAL, Paris, École des chartes, 2014 («Mémoires et documents de l’Ecole des chartes», 95), pp. 344.

1 Le dit de la fleur de lis, écrit en 1338, au moment où le conflit franco-anglais s'annonce, est un songe allégorique dont le but est d'exalter la dignité royale; il est conservé dans deux manuscrits (Ars. 3646 et BNF, lat. 4120) «largement fautifs» (p. 136). Piaget le publie en 1936, mais, prisonnier de son époque, il est incapable d'en saisir la complexité littéraire et en donne une édition simplement documentaire (hâtive par bien des aspects et fournissant un texte banalisé, cf. pp. 13-14), source de nombreux contresens dans les travaux qui ont suivi, notamment chez les historiens. La présente édition entend donc rendre justice à l'œuvre et, profitant du fait que le texte est relativement court (1336 octosyllabes), examiner de manière approfondie les nombreux problèmes qu'il pose et fournir un modèle d'ecdotique. Très soignée, elle donne d'abord les deux versions manuscrites, imprimées en regard, ensuite le texte est établi critiquement. La méthode est conservatrice, mais non imitative, dans l'édition synoptique, résolument reconstructionniste dans la suivante (même si elle s'appuie sur un manuscrit de base).

2 Le volume, au-delà de la mise à disposition d'un dit difficile et important dans l'histoire intellectuelle, est un véritable outil pédagogique. Son intérêt est plus grand encore du point de vue du statut du texte qui y est affirmé. Après des décennies d'approche archéologique, plus ou moins réfléchie, le témoin n'est plus saisi comme une trace à respecter, dont il s'agit de restituer l'altérité fondamentale, même si l'on tend à éviter les difficultés de compréhension inutiles. Ici, tout en ménageant littéraires et linguistes grâce à l'édition synoptique et s'adressant aux «historiens, qui cherchent à interpréter le message de Guillaume de Digulleville, considéré comme fait historique, plutôt que 
l'un de ses avatars déformés» (p. 136), l'éditeur propose un «artefact» (ibidem), une nouvelle version, dans une certaine mesure transhistorique et orientée «vers le lecteur moderne non-linguiste» (p. 142). Les textes des manuscrits étant reproduits fidèlement dans l'édition synoptique, le débat sur une telle attitude n'a même pas lieu d'être, mais on mesure la distance qui la sépare des pratiques courantes.

L'introduction présente l'œuvre et justifie la nouvelle édition. Elle examine ensuite l'attribution, le titre, la structure du dit, avant de donner l'interprétation du contenu. Sont analysés d'une part les thèmes politiques, d'autre part la construction allégorique du signe, la fleur de lis. A l'inverse de la démarche habituelle dans l'écriture allégorique, allant du signifiant au signifié, Guillaume relate dans son songe la production du signe à partir du signifié, le signe étant l'ouvrage de personnifications allégoriques divines qui le destinent à la royauté. Le dit lui-même "peut ainsi se lire comme une "allégorie de l'écriture allégorique"»(p. 81), c'est-à-dire comme une métaphore du travail de l'écrivain (même si le propos est à nuancer, cf. p. 84). La description des manuscrits suit, ainsi que des Remarques linguistiques (pp. 96-125) précises et fouillées, ne visant pas la description de la langue, mais l'examen des données utiles à l'établissement du texte. L'étude de la versification (pp. 125-131) et celle de la tradition textuelle (pp. 131-135), l'explicitation argumentée des principes d'édition (pp. 135-143) et la bibliographie (pp. 145-160) terminent l'introduction. L'Edition synoptique des deux manuscrits et l'Edition critique (accompagnée d'un riche apparat de notes) du dit suivent. Le glossaire (pp. 311-334), l'Index nominum et l'Index rerum complètent l'ouvrage. 